\title{
The ethics of listening and responding to patients' narratives: implications for practice
}

Recently I did a home visit during an outof-hours session which impacted on me for reasons that, at the time, I sensed, but did not fully comprehend. In trying to understand the event, reading around the subject of identity provided a lens through which I was able to recognise why I derived satisfaction from both the process and outcome of the consultation.

A housecall was requested for an older lady suffering from dizziness and vomiting. She had been taken home from an event she had been attending with her adult son, who has complex medical and social needs. I initially approached the consultation in my usual fashion, using the interrogative questioning of the medical model in order to frame the issues in medical terms. The patient was resistant to answering these questions, instead wishing to tell her story in her own words. I felt irritated when she started relating her symptoms to a minor head injury, which occurred 3 days previously. My time was pressured and I could see little relevance to her current symptoms given the innocuous nature of the injury and the time lapse between it and the onset of symptoms. However, the more I listened the more I was able to appreciate the relevance and importance of her narrative.

She looks after her son and her husband, who suffers from dementia, with little support. Her injury had been the result of her having hit her head on a cupboard door while cooking a meal for them. She contacted her GP in the days following the injury as she had developed a headache which was only partially relieved by paracetamol. Her GP prescribed codydramol. Currently she was anxious because her symptoms of dizziness and vomiting would prevent her preparing the evening meal for her husband and son. As her narrative progressed it became clear to both of us that her symptoms were indeed the result of her head injury although its nature was iatrogenic, the side effects of co-dydramol. Physical examination revealed no significant findings. We then explored the potential support available to her and she suggested contacting one of her close friends, who would organise to feed her son and husband that evening. She wished to continue to look after her son and husband as before, but recognised that this would be difficult in the short term and agreed to me contacting social services.

This case illustrated the effectiveness and importance of listening and responding to patients' narratives and revealed important ethical dimensions at discursive and relational levels. At a discursive level medical professionals are in a position of power relating to who frames issues and whose version of reality holds sway. At the micro-level analysis of discursive systems control of language the vehicle through which people name, describe and depict - can be used to manage perceptions. Through language our thoughts and experiences are organised and the issues to which we address our attention framed. ${ }^{1}$ It therefore has a constitutive moral relation to its objects. ${ }^{2}$ Initially framing my perspectives in the language of medicine had the potential to silence the patient's version of reality. By my avoiding framing the issues in medical terms, in response to the patient's resistance, she was enabled to relate from her own frame of reference. By entering into her frame of reference, while still maintaining my own perspective, the space was provided for us to test meaning and affirm her identity.

At the macro-level of analysis medical discourses, fields of knowledge operating within the profession often influence how doctors act by helping establish norms which are socialised in medical students and doctors. They 'declare the bases for deciding what is true and authorising certain people to speak while making others silent or less authoritative'. ${ }^{3}$ 'Expert' practitioners can claim 'cognitive authority'4 over the stories of practice and have the capacity to silence other stories by adopting what Frye terms the 'arrogant eye, ${ }^{5}$ where perspectives not fitting the master medical discourse are dismissed or degraded. There are limits to this power, as was demonstrated by my patient with her capacity to resist domination. I was also able to resist by adopting what Frye terms a 'loving gaze, ${ }^{5}$ where mutuality and respect prevented her discursive account being delegitimised. ${ }^{6}$

At a relational level, to have simply reflected on my own interpretations without considering, what Levinas ${ }^{7}$ terms the 'face of the other,' and not acknowledging her construction of meaning, in light of my own, would have been unethical. My experience and constructions could have become very powerful, and given that as a doctor I was already in a position of power, my constructions could have occluded the experience of the patient and may have disempowered her. ${ }^{8}$ Meaning develops in response to the other, what Kearney ${ }^{9}$ has termed 'radical intersubjectivity'. It is always a becoming, dialogically constituted between the patient and doctor. Practitioners have considerable power to grant or withhold recognition and grant or withhold spaces in which divergent accounts of meaning and identity can be expressed and tested. ${ }^{6}$ Patients should be co-creators of meaning during consultations. ${ }^{10} \quad$ In such ethical relationships we are answerable to the patient. ${ }^{11}$ Without an adequate consideration we are in danger of objectifying and manipulating patients 'in accordance with an egocentric self interest'. ${ }^{12}$ 
The manner in which doctors use or misuse relationships and language to 'construct' their patients, construct versions of reality, construct meaning, and wield cognitive authority has major implications for everyday practice. Chapman $^{13}$ advocates a phronetic approach grounded in the everyday where the doctor is conscious of and attempts to wield power in an ethical manner. This approach is informed by Frye's 'loving eye'. ${ }^{5}$ Attention to the ways patients construct meanings and the creation of environments that foster empathic, dialogic communication are important consultation skills for doctors. General practice with its process of reflective, case-based education is conducive to fostering such an approach. It requires awareness and role modelling of these skills by GP educators.

However, this approach is at odds with clinical environments that promote doctors as experts and emphasise evidence and efficiency. In such environments listening and responding to patients' narratives takes time and is often not valued, particularly where the benefits cannot be directly measured. To be answerable to the patient requires the doctor to recognise her/his own limitations and demands openness and humility as opposed to pride and arrogance. This can run contrary to environments that are hierarchical and expert-centred. ${ }^{8}$ This is less likely in general practice with its, hopefully, nonhierarchical structure, patient-centred ethos and valuing of openness and humility. However, the changing ethos of target driven practice and commissioning threaten to compromise this situation.

\section{John GS Goldie}

\section{REFERENCES}

1. Lather P. Getting Smart: feminist research and pedagogy with/in the postmodern. New York, NY:
Routledge, 1991.

2. Sandywell B. Reflexivity and the crisis of western reason: logical investigations. London: Routledge, 1996.

3. Foucault M. The archeology of knowledge. London: Tavistock, 1974.

4. Addleson KP. The man of professional wisdom. In: Harding S, Hintikka M (eds). Discovering reality. Boston, MA: D Reidel, 1983.

5. Frye M. The politics of reality. Freedom, CA: Crossing, 1993.

6. Nelson HL. Damaged identities: narrative repair. Icthaca, NY: Cornell University Press, 2001.

7. Levinas E. Totality and infinity. Pittsburgh, PA: Dusquesne University Press, 1969.

8. Kinsella E. Ethical overtones in surprising locations. In: Rapport F, Wainwright $\mathrm{P}$ (eds). The self in health and illness. Oxford: Radcliffe, 2006.

9. Kearney R. The wake of imagination. London: Routledge, 1988.

10. Bakhtin M. Toward a philosophy of the act. Austin, TX: University of Texas Press, 1993.

11. Bakhtin M. The Bakhtin reader. London: Edward Arnold, 1994.

12. Gardiner M. Bakhtin and the metaphorics of perception. In: Heywood I, Sandywell B (eds). Interpreting Visual cultures: explorations in the hermenutics of the visual. London: Routledge, 1999.

13. Chapman V. On 'knowing one's self', self writing, power and ethical practice: reflections from an adult educator. Studies in the Education of Adults 2003; 35: $35-53$.

DOI: 10.3399/bjgp11X568143 